\title{
Age exacerbates microglial activation, oxidative stress, inflammatory and NOX2 gene expression, and delays functional recovery in a middle-aged rodent model of spinal cord injury
}

Ramona E. von Leden ${ }^{1,2^{*}}$ D, Guzal Khayrullina ${ }^{1,2}$, Kasey E. Moritz ${ }^{1}$ and Kimberly R. Byrnes ${ }^{1,2}$

\begin{abstract}
Background: Spinal cord injury (SCl) among people over age 40 has been steadily increasing since the 1980 s and is associated with worsened outcome than injuries in young people. Age-related increases in reactive oxygen species (ROS) are suggested to lead to chronic inflammation. The NADPH oxidase 2 (NOX2) enzyme is expressed by microglia and is a primary source of ROS. This study aimed to determine the effect of age on inflammation, oxidative damage, NOX2 gene expression, and functional performance with and without SCl in young adult (3 months) and middle-aged (12 months) male rats.

Methods: Young adult and middle-aged rats were assessed in two groups—naïve and moderate contusion SCl. Functional recovery was determined by weekly assessment with the Basso, Beattie, and Breshnahan general motor score (analyzed two-way ANOVA) and footprint analysis (analyzed by Chi-square analysis). Tissue was analyzed for markers of oxidative damage (8-OHdG, Oxyblot, and 3-NT), microglial-related inflammation (Iba1), NOX2 component (p47 ${ }^{\mathrm{PHOX}}, \mathrm{p} 22^{\mathrm{PHOX}}$, and gp91 ${ }^{\mathrm{PHOX}}$ ), and inflammatory (CD86, CD206, TNFa, and NFkB) gene expression (all analyzed by unpaired Student's $t$ test).

Results: In both naïve and injured aged rats, compared to young rats, tissue analysis revealed significant increases in 8-OHdG and Iba1, as well as inflammatory and NOX2 component gene expression. Further, injured aged rats showed greater lesion volume rostral and caudal to the injury epicenter. Finally, injured aged rats showed significantly reduced Basso-Beattie-Bresnahan (BBB) scores and stride length after SCl.

Conclusions: These results show that middle-aged rats demonstrate increased microglial activation, oxidative stress, and inflammatory gene expression, which may be related to elevated NOX2 expression, and contribute to worsened functional outcome following injury. These findings are essential to elucidating the mechanisms of age-related differences in response to $\mathrm{SCl}$ and developing age-appropriate therapeutics.
\end{abstract}

Keywords: Spinal cord injury, Aging, NOX2, Microglia, Inflammation

\footnotetext{
* Correspondence: Ramona.von-leden.ctr@usush.edu

${ }^{1}$ Neuroscience Program, Uniformed Services University, 4301 Jones Bridge Road, Bethesda, MD 20814, USA

2Department of Anatomy, Physiology, and Genetics, Uniformed Services

University, Room C2099, 4301 Jones Bridge Road, Bethesda, MD 20814, USA
} 


\section{Background}

There are over 250,000 people in the USA currently living with a spinal cord injury (SCI), and over 15,000 new cases are documented every year [1]. These injuries cause permanent motor, autonomic, and sensory function loss [2]. Reduced cell viability and neuron, astrocyte, and oligodendrocyte loss are seen acutely after SCI [3]. White matter and axon loss, glial scar formation, and inflammation are seen chronically after injury, in the days to months following onset [3].

SCI is largely studied in the young adult population due to the high propensity of injuries from athletic and military injuries and car accidents; however, there has been a notable increase in age of onset in recent decades [4]. In the 1970s, the average age at onset of injury was 29 , but the average age has now increased to 42 [1]. Aging tissue shows progressive DNA damage beginning by the age of 40, causing increased expression of genes involved in stress response and repair, including immune and inflammatory genes [5]. Further, aging causes changes to hormones and cellular function associated with increased co-morbidities, lengthened recovery time, reduced functional recovery, and prolonged chronic inflammation after SCI [6].

One notable change to the cellular environment with aging is an increase in oxidative stress caused by the buildup of reactive oxygen species (ROS) over time $[7,8]$. The superoxide producing NADPH oxidase (NOX) enzyme is a major source of ROS [9]. The NOX2 isoform has been shown to be the most responsive to injury and is present on microglia, the primary inflammatory cell type of the central nervous system [10]. Microglia are found in a resting state in uninjured tissue, with ramified cell body and long processes. When activated, they take on a proinflammatory state with an amoeboid-like cell shape, releasing cytotoxic and inflammatory mediators [11]. Activated microglia are found in the spinal cord cellular environment within $24 \mathrm{~h}$ post-injury and have a maintained, low-level activated presence at 60 days post-injury (dpi) [11].

In animal models of traumatic brain injury (TBI), aged microglia show alterations to morphology and activation compared to younger microglia [12-14]. In uninjured aged brain tissue, microglia demonstrate a hypertrophic or partially activated cell shape, considered a "primed" activation state [14]. When injured, these aged cells show a hyperactive response to injury compared to younger cells, resulting in extended chronic inflammation [14]. Previous work has demonstrated that in the spinal cord, compared to the brain, there is a significantly greater inflammatory response and recruitment of macrophages and neutrophils to trauma [15-17].
Therefore, findings in the aging brain may not accurately indicate what will occur in the spinal cord.

Few studies have examined how age influences microglial activation and/or oxidative stress in the spinal cord [18-21] and the role NOX2 plays in this process [22]. Work in our lab has characterized the role of NOX2 in SCI [23], demonstrating that inhibition of NOX2 improves functional recovery and decreases oxidative stress and inflammation in a young adult rodent model of SCI [24]. Previous work on age-related cellular alterations after spinal cord injury have been performed in mice [22] and aged female rats [19], while in this paper we examine a middle-aged male rat model of SCI as the average age of onset of human SCI is 42 years old. Based on previous work showing age-related alterations after injury in the brain $[12,14,25]$ and spinal cord [18, 19, $21,26]$, we investigated microglia, NOX2 components, and ROS prior to and chronically after injury (30 dpi). We now show that microglial and NOX2 gene expression and ROS production are increased in middle-aged rats, demonstrating age-related alterations in the spinal cord.

\section{Methods}

\section{Animals}

Male Sprague Dawley rats were given free access to food and water and a 12-h light/12-h dark cycle. Young adult rats (3 months old: 300-500 g; Taconic, Germantown, MD: $n=24$; Harlan, Frederick, MD: $n=6$ ) from Harlan were used in addition to rats from Taconic in pilot naïve and $30 \mathrm{dpi}$ injured study groups for immunohistochemistry and functional assessment. No significant difference was noted between groups from different vendors; therefore, data from all vendors are presented together. Rats were housed for 1 week prior to undergoing surgery or assessment for naïve studies. Middle-aged rats (12-months-old, retired breeders: 400-600 g; Harlan, Frederick, MD: $n=28$ ) were acquired at 10 months of age and gentled twice a week until they had matured to 12 months of age, at which point they underwent surgery or assessment for naïve studies. One 12-month-old injured rat naturally perished at $20 \mathrm{dpi}$ and was removed from behavioral testing data (final $n=17$ behavioral analysis). Two 3-month-old injured rats were not included in tissue analysis as tissue was damaged in processing (final $n=14$ tissue analysis). All 12-month-old injured rats were subjected to full behavioral battery, but the behavioral battery for the first cohort of 3-month-old injured rats did not include footprint analysis testing, which means that the total number of animals tested in the 3 -month-old group was smaller than that in the 12month-old rats $(n=5 / 103$-month-old rats able to perform $28 \mathrm{dpi}$ footprint analysis, $n=7 / 18$ 12- 
month-old rats able to perform 28 dpi footprint analysis). After functional testing, groups were divided among tissue analysis groups for histological, immunohistochemical, or biochemical analysis as designated prior to injury. All animal procedures were approved by the Uniformed Services University IACUC and complied fully with the principles set forth in the "Guide for the Care and Use of Laboratory Animals" prepared by the Committee on Care and Use of Laboratory Animals of the Institute of Laboratory Resources, National Research Council (DHEW pub. No. (NIH) 85-23, 2985); this manuscript has been written in accordance with the ARRIVE (Animal Research: Reporting In Vivo Experiments) guidelines [27].

\section{Contusion spinal cord injury}

Contusion SCI was performed in rats $(n=35)$ (see Table 1 for breakdown of animal groups) as described previously [28]. Briefly, rats were anesthetized with isoflurane (4\% induction, $2.5 \%$ maintenance in $50 \% \mathrm{O}_{2}$ ), and a laminectomy was performed at vertebral level T9 to expose the spinal cord. Moderate injury (150 kDynes force, 1500- $\mu$ displacement, $127-\mathrm{mm} / \mathrm{s}$ velocity, 1-s dwell time) was induced with the Infinite Horizons Impactor (Precision Systems Incorporated, Natick, MA). Naïve animals $(n=22)$ received no surgery or anesthesia. Post-injury care included dual housing on diamond soft bedding (Harlan Laboratories, Frederick, MD), twice daily bladder expressions until spontaneous micturition returned, and analgesic supplementation to drinking water for $48 \mathrm{~h}$ following injury (Children's Tylenol; acetaminophen, $200 \mathrm{mg} / \mathrm{kg}$ ).

\section{Functional assessment}

The Basso-Beattie-Bresnahan (BBB) scale was used to assess functional neurological recovery, as detailed previously [29]. Performance of the left and right hind limbs on a scale from 0 (no spontaneous movement) to 21(normal locomotion) was averaged to obtain the total BBB on 1, 7, 14, 21, and 28 dpi. More detailed locomotion was assessed using the "footprint analysis test," modified from Kunkel-Bagden et al. [30] and performed on the same days as BBB assessment. Subjects' hind paws were pressed to an inkpad to dye their hind feet and were then allowed to walk across a sheet of paper lining a long and narrow runway (6.5 in. wide, 76 in. long) to ensure animals walked in a straight line for analysis. Prints were analyzed for width of toe spread and length of stride length (in $\mathrm{mm}$ ). Subjects' footprints were only analyzed if they had regained ability to walk with support on the hind limbs (a minimum BBB score of 11 ), and percentage of animals who had regained the ability to perform the task was analyzed by age group at each assessment day.

\section{Histology and lesion volume}

At $30 \mathrm{dpi}$, rats were anesthetized with Euthasol (pentobarbital sodium and phenytoin sodium; $200 \mathrm{mg} / \mathrm{kg}$, IP) and intracardially perfused with $10 \%$ buffered formalin (Fisher Scientific, Hampton, New Hampshire). A 1-cm block of spinal cord tissue was dissected, extending $5 \mathrm{~mm}$ rostral and caudal from the center of the lesion site (or from the T9 vertebral site for naïve animals). Tissue was sectioned into $20-\mu \mathrm{m}$ axial sections, and every third slice was saved for histological analyses. To determine lesion volume, tissue was processed with a standard H\&E stain. Lesion volume from H\&E images collected with NanoBrightfield Software (Hamamatsu Corporation, Middlesex, NJ) were quantified using the Cavalieri method as previously described [31, 32]. Ten sections were analyzed per animal at even intervals throughout the spinal cord from $360-\mu \mathrm{m}$ pre-lesion epicenter $(0-360 \mu \mathrm{m}$ on histogram in Fig. 5a) through lesion epicenter (between 360 and $540 \mu \mathrm{m}$ on histogram) to $360 \mu \mathrm{m}$ post-epicenter (540-900 $\mu \mathrm{m}$ on histogram) to provide an analysis of volume of lesion throughout the spinal cord.

\section{Immunohistochemistry}

Standard fluorescent immunohistochemistry was performed on tissue sections from animals $30 \mathrm{dpi}$ obtained as described above. Iba1 (microglia, 1:100; Wako Bioproducts, Cat\# 019-19741 RRID:AB_839504; Richmond, VA) and 8-OHdG (DNA oxidation, 1:500; Abcam, Cat\# ab62623 RRID:AB_940049; Cambridge, MA) were used as primary antibodies, with visualization by fluorescent

Table 1 Number of animals per group for all experiments in study

\begin{tabular}{llllll}
\hline Number of animals per group and experiment & & & & \\
\hline Age & Injured/naïve & Function & Immunohistochemistry & Lesion volume & Biochemistry/PCR \\
\hline 3 months old & Naïve & 12 & 4 & 0 & 4 \\
12 months old & Naïve & 10 & 4 & 0 & 4 \\
3 months old & Injured & 18 & 4 & 6 & 4 \\
12 months old & Injured & 17 & 4 & 6 & 4
\end{tabular}

Animals were first divided by age ( 3 or 12-months old) and injury type (naïve or injured). Functional analysis was performed on all animals in study. Animals used in function experiments were sacrificed and divided into subgroups for tissue experiments (immunohistochemistry, lesion volume, and biochemistry/PCR) 
secondary antibodies (Alexa-Fluor Secondaries, 1:500; Molecular Probes, Eugene, OR). Negative controls (sections not stained with primary antibody) were used to confirm specificity of secondary antibodies. Immunofluorescent images were captured under the same fluorescence conditions and exposure time on a NanoZoomer system (Hamamatsu, Bridgewater, NJ) or an Olympus BX43 microscope (Olympus America). Immunofluorescence was quantified using pixel density measurement in Scion Image as previously described [33]. Ten axial sections were analyzed per animal starting caudally at the first sign of lesion, then at even intervals rostrally through the spinal cord for $1 \mathrm{~cm}$ to provide analysis throughout the lesion. Analysis was performed on gray matter directly adjacent to the lesion site at $20 \times$ magnification. The average pixel density of all ten sections was reported for each animal.

\section{Comparative RT-PCR}

A $10-\mathrm{mm}$ section of the spinal cord, centered at the lesion epicenter, was dissected and immediately frozen on dry ice. The TRIzol $^{\circ}$ protein and mRNA extraction method (Invitrogen, Carlsbad, CA) was employed so that each sample could be used for both western blotting and mRNA quantification. Briefly, RNA was extracted from each cord sample individually using TRIzol $^{\circ}$ reagent and chloroform, then purified with the Qiagen RNeasy kit (\#74104, Qiagen, Hilden, Germany). RNA concentration was measured using the Nanodrop system (Thermo Scientific, Wilmington, DE). Complementary DNA (cDNA) conversion was performed from $1 \mu \mathrm{g}$ of RNA using a Veriti thermal cycler (Applied Biosciences, Waltham, MA) and a high-capacity cDNA conversion kit (Applied Biosciences, Waltham, MA) using the manufacturer's protocol. Quantitative real-time PCR (qRT-PCR) was performed using the StepOnePlus Real-Time PCR System
(Applied Biosciences, Waltham, MA) according to the manufacturer's instructions. To determine changes in gene expression, primers were designed using the Primer-Blast tool, then obtained from Integrated DNA Technologies (IDT, Coralville, IA; see Table 2 for detailed primer information). Reported gene expression values were determined using the $\Delta \Delta$ CT method: raw value of each sample normalized first to internal control (GAPDH) and then to the control group (3 months).

\section{Western blot and Oxyblot}

Protein from frozen tissue samples was isolated in TRIzol ${ }^{\circ}$ reagent (Invitrogen, Carlsbad, CA). Detection of protein oxidation was performed by processing protein samples using the Oxyblot Protein Oxidation Detection Analysis Kit (Millipore, Billerica, MA) according to the manufacturer's protocol. For both Oxyblot and western blotting, $15 \mu \mathrm{g}$ of sample protein was run in a Mini-PROTEAN ${ }^{\circ}$ TGX $^{\text {ma }}$ Precast Gel (Bio-Rad, Hercules, CA) and transferred to a Trans-Blot ${ }^{\circ}$ Turbo $^{\text {TM }}$ (Bio-Rad) nitrocellulose membrane. Antibodies raised against 3-nitrotyrosine (5 $\mu \mathrm{g} / \mathrm{ml}$; Abcam, Cat\# ab61392, RRID:AB_942087) were probed overnight at $4{ }^{\circ} \mathrm{C}$. Immune complexes and oxidated proteins were detected with appropriate secondary antibodies and chemiluminescence reagents (Pierce).

For both Oxyblot and western blots, GAPDH $(0.5 \mu \mathrm{g} /$ ml; Millipore, Cat\# MAB374 RRID:AB_2107445) was used as a control for gel loading and protein transfer. $\mathrm{NIH}$ ImageJ was used to assess pixel density of resultant blots for quantitation.

\section{Statistics}

Sample sizes were calculated based on our previous work [34]. All assays were carried out by investigators blinded to subject group. Quantitative data are presented

Table 2 Gene primers tested in comparative RT-PCR experiments

\begin{tabular}{|c|c|c|}
\hline Gene & Sense & Antisense \\
\hline CD86 & 5'-TGCTCATCTAAGCAAGGATACCCG-3' & 5'-CGACTCGTCAACACCACTGTCCTG-3' \\
\hline CD206 & 5'-GGATTGTGGAGCAGATGGAAG-3' & 5'-CTTGAATGGAAATGCACAGAC-3' \\
\hline $\mathrm{p} 22^{\mathrm{PHOX}}$ & 5'-GACGCTTCACGCAGTGGTACT-3' & 5'-CACGACCTCATCTGTCACTGG-3' \\
\hline $\mathrm{p} 47^{\mathrm{PHOX}}$ & 5'-CAGAATGTTGCCTGGTTG-3' & 5'-GTCCCCTCCCTTAGATGA-3' \\
\hline gp91 ${ }^{\text {PHOX }}$ & 5'-CTTCACACGGCCATTCACAC-3' & 5'-GTCATAGGAGGGTTTCCGGC-3' \\
\hline TNFa & 5'-GGCAGCCTTGTCCCTTGAAGAG-3' & 5'-GTAGCCCACGTCGTAGCAAACC-3' \\
\hline NFKB & 5'-GTGCAGAAAGAAGACATTGAGGTG-3' & 5'-AGGCTAGGGTCAGCGTATGG-3' \\
\hline iNOS & 5'-CAGCCCTCAGAGTACAACGAT-3' & 5'-CAGCAGGCACACGCAATGAT-3' \\
\hline Arg-1 & 5'-CAGTATTCACCCCGGCTACG-3' & 5'-GCCTGGTTCTGTTCGGTTTG-3' \\
\hline CD68 & 5'-TGTACCTGACCCAGGGTGGAA-3' & 5'-GAATCCAAAGGTAAGCTGTCCGTAA-3' \\
\hline IL10 & 5'-CAAGGAGCATTTGAATTCCC-3' & 5'-GGCCTTGTAGACACCTTGGTC-3' \\
\hline GAPDH & 5'-GCTGGTCATCAACGGGAAA-3' & 5'-ACGCCAGTAGACTCCACGACA-3' \\
\hline
\end{tabular}

Table provides sense and antisense sequences for each gene tested in this study. Genes investigated that showed no significant difference by age in either naïve or injured animals were omitted from results 
as mean \pm standard error of the mean (SEM). General motor performance using the BBB test was analyzed using a two-way ANOVA with Tukey's multiple comparison's post hoc test. Ability to plantar step in footprint analysis task was analyzed using Chi-square analysis. Footprint analysis test, immunohistochemistry, biochemistry, and qRT PCR were analyzed using the Student $t$ test. All statistical tests were performed using the GraphPad Prism Program, Version 6.03 for Windows (GraphPad Software, San Diego, CA). A $p$ value $<0.05$ was considered statistically significant.

\section{Results}

Uninjured middle-aged animals show altered stepping pattern in footprint analysis

Footprint analysis of toe spread and stride length in uninjured animals revealed an alteration in motor function in middle-aged animals compared to young animals (Fig. 1a). Toe spread was measured from the thumb toe (toe 1) to the pinky toe (toe 5) in the hind paws. Twelve-month-aged rats showed a significantly wider toe spread than 3-month-aged rats $(t(20)=4.98$, $p=0.0005)$. Stride length was measured as the length in millimeter between each consecutive step in the hind paws. Though not significant, 12-month-aged rats showed a trend toward longer strides than 3-monthaged rats (Fig. 1b; $t(20)=1.97, p=0.0627$ ), indicating that overall stepping patterns are altered with age.

\section{Microglial activation and pro-inflammatory gene expres-} sion is altered with age

To determine if aged tissue showed basal differences in microglial activation, uninjured tissue from 3- and 12month-old rats was immunostained with the microglial marker Iba-1 (Fig. 2a) and processed for comparative RT-PCR for expression genes associated with microglial activation and NOX2 components. Our findings showed significantly increased Iba-1 staining $(t(6)=2.59$, $p=0.0496)$ in 12-month-aged rat tissue compared to 3month-aged rats (Fig. 2b). Comparative RT-PCR results (Fig. 2c) showed significantly increased gene expression in 12-month-aged rats of the pro-inflammatory phenotype marker CD86 $(t(6)=7.46, p=0.0050)$ compared to 3 -month-aged rats. No significant difference by age was found in any other genes probed, including the antiinflammatory phenotype marker CD206, transcription factor NFKB, or inflammatory cytokine TNFa (Table 3). Relative fold changes between 3- and 12-month-old rats for all genes tested listed in numerical form can be found in Table 3 under "naïve."

\section{Middle-aged rats show increased gene expression of NOX2 cytosolic subunit component $\mathrm{p} 47^{\mathrm{PHOX}}$}

To determine if NOX2 activity and expression were influenced by age, uninjured tissue from 3- and 12-month-old rats was processed for comparative RT-PCR and analyzed for target gene expression. Gene expression of the activated cytosolic subunit $\mathrm{p} 47^{\mathrm{PHOX}}$ was significantly increased in 12-month-aged rats compared to that in 3month-aged rats $(t(6)=3.47, p<0.0001$; Fig. $2 \mathrm{~d})$. However, gene expression of the activated membrane bound NOX2 components $\mathrm{p} 22^{\mathrm{PHOX}}$ and gp91 ${ }^{\mathrm{PHOX}}$ did not reveal any significant difference by age.

\section{ROS production is altered with age}

To determine if tissue showed basal differences in ROS production with age, uninjured tissue from 3- and 12month-old rats was immunostained with the DNA

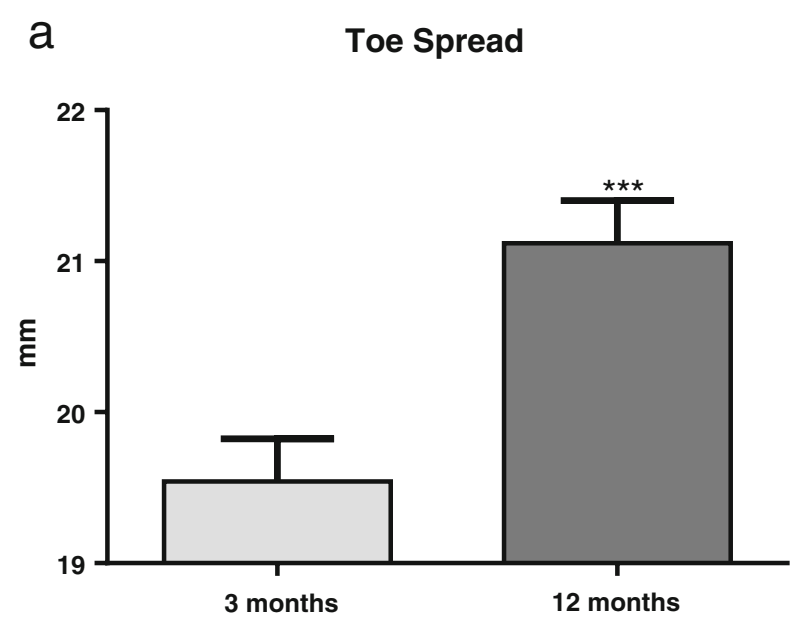

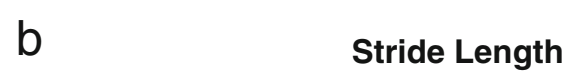

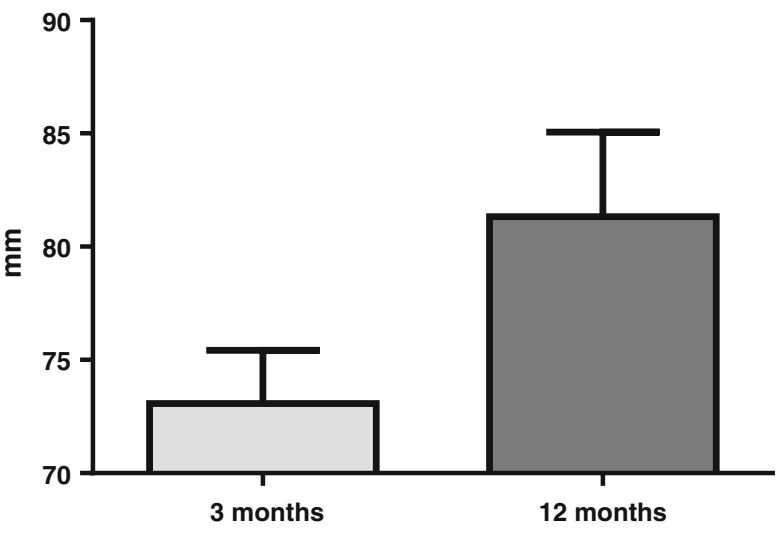

Fig. 1 Uninjured aged animals show altered stepping pattern in footprint analysis. a Uninjured 12-month-old rats $(n=10)$ have significantly wider toe spread than 3-month-old rats $(n=12)$. $\mathbf{b}$ Uninjured 12-month old-rats show a trend toward increased stride length compared to 3-month-old rats, supporting toe spread findings. ${ }^{* *} p<0.001$. Bars represent mean \pm SEM 


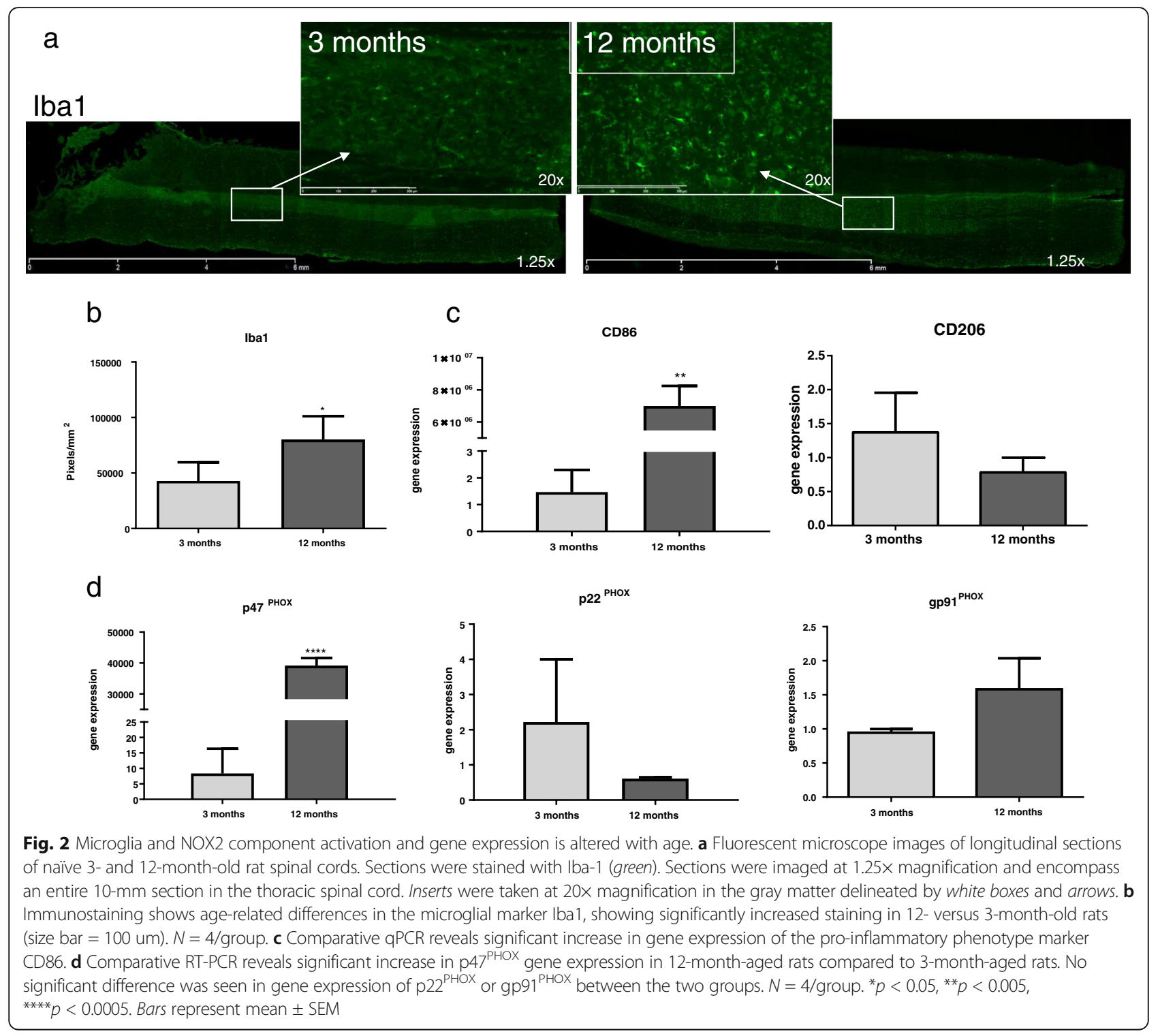

oxidation marker 8-OHdG (Fig. 3a), Oxyblot analysis was performed to determine protein oxidation, and western blotting was performed to determine levels of 3NT, a marker of protein nitrosylation. Our findings showed that 12-month-aged rats compared to 3-monthaged rats demonstrated a significant increase in 8OHdG staining $(t(6)=3.06, p=0.0281$; Fig. $3 \mathrm{~b})$ and a trend toward increased protein oxidation via Oxyblot $(t(6)=2.18, p=0.0946$; Fig. 3c). Western blotting did not show any difference in protein nitrosylation between the two ages (Fig. 3d).

\section{Middle-aged rats show diminished motor function recovery after spinal cord injury}

Next, we examined both middle-aged and young animals after moderate contusion SCI to investigate how age alters response to injury. Our results from the $\mathrm{BBB}$ general motor test showed worsened performance by aged animals after injury (Fig. 4). Twelve-month-old rats showed worsened performance compared to 3-monthold rats at all time points except $1 \mathrm{dpi}$, indicating significantly impaired recovery to injury $[\mathrm{F}(1.33)=12.81$, $p<0.0001$; Fig. 4a]. At 1 dpi, 12- and 3-month-old rats averaged a score of $0.471 \pm 0.2827$ and $1.000 \pm 0.485$ respectively, indicating no stepping ability with only slight movement of one joint on one limb. At $7 \mathrm{dpi}$, the 3month-old group has progressed to a mean of $6.583 \pm 1.188$, indicating extensive movement in all multiple joints, while the 12-month-old group remained at an average score of $0.529 \pm 0.208$. By $14 \mathrm{dpi}$, the 3 -month-old group continued to show steady improvement with a BBB score of $10.970 \pm 1.217$, with occasional weight-supported 
Table 3 Comparative gene fold changes for all genes tested by injury group

\begin{tabular}{|c|c|c|c|c|}
\hline \multicolumn{5}{|c|}{ Comparative fold change by injury group } \\
\hline \multicolumn{2}{|l|}{ Naïve } & \multirow{2}{*}{$\begin{array}{l}\text { Gene } \\
\text { tested }\end{array}$} & \multicolumn{2}{|l|}{$30 \mathrm{dpi}$} \\
\hline 3 months old & 12 months old & & 3 months old & 12 months old \\
\hline $1.467 \pm 0.8292$ & $* * 6.993 \times 10^{6} \pm 1.258 \times 10^{6}$ & CD86 & $1.096 \pm 0.2886$ & $* * 1.253 \times 10^{6} \pm 145,818$ \\
\hline $1.371 \pm 0.5850$ & $0.7830 \pm 0.2167$ & CD206 & $1.104 \pm 0.3465$ & $* * 139,991 \pm 24,361$ \\
\hline $2.217 \pm 1.785$ & $0.6052 \pm 0.04079$ & $\mathrm{p} 22^{\mathrm{PHOX}}$ & $1.030 \pm 0.1825$ & *20678 \pm 6017 \\
\hline $8.352 \pm 8.037$ & $* * * * 39,131 \pm 2480$ & $\mathrm{p} 47^{\mathrm{PHOX}}$ & $7.739 \pm 5.672$ & $* 1.225 \times 10^{6} \pm 473,918$ \\
\hline $0.9453 \pm 0.05264$ & $1.583 \pm 0.4531$ & gp91 ${ }^{\text {PHOX }}$ & $0.9421 \pm 0.08263$ & $* 1.948 \pm 0.4574$ \\
\hline $3.229 \pm 2.839$ & $163.1 \pm 141.8$ & TNFa & $0.6954 \pm 0.3801$ & *11.55 \pm 2.502 \\
\hline $1.226 \pm 0.5548$ & $0.8387 \pm 0.6209$ & NFkB & $1.027 \pm 0.1751$ & $* 4.108 \pm 0.7734$ \\
\hline $44.06 \pm 22.85$ & $0.01669 \pm 0.01419$ & iNOS & $1.109 \pm 0.3358$ & $1.069 \pm 0.4000$ \\
\hline $3.118 \pm 2.773$ & $1230 \pm 794.0$ & Arg-1 & $1.047 \pm 0.2304$ & $1.382 \pm 0.03944$ \\
\hline $0.4958 \pm 0.4531$ & $0.3324 \pm 0.02472$ & CD68 & $1.104 \pm 0.3346$ & $1.011 \pm 0.3394$ \\
\hline $2.438 \pm 1.521$ & $7.806 \pm 4.643$ & IL10 & $1.051 \pm 0.2427$ & $1.057 \pm 0.1975$ \\
\hline
\end{tabular}

Table demonstrates how age affects gene expression before and after injury. The average of the 3-month-old group in both the naïve and injury groups was considered the control mean value. Each individual sample's fold change was compared to the control mean. Fold changes are presented in table as mean values of all samples in each group \pm SEM. $N=4$ /group

${ }^{*} p<0.05,{ }^{* *} p<0.005,{ }^{* * *} p<0.0005$

steps but no limb coordination, and the 12-month-old group showed sweeping of the feet with no weightbearing steps, averaging $6.971 \pm 1.309$. At 21 and $28 \mathrm{dpi}$, improvement in the 3-month-old group was still steady $(13.310 \pm 1.009$ and $14.42 \pm 1.070$, respectively), showing consistent weight-bearing plantar stepping with coordinated limb movements, while the 12-month-old group reached a max performance of $9.618 \pm 1.202$ at $21 \mathrm{dpi}$, with weight-bearing plantar stepping but only occasional coordinated limb movements and never improved beyond that score. This comparison demonstrates not only that the 12-monthold groups' recovery was diminished in comparison with that of the 3-month-old but also that the overall speed of recovery was delayed-the improvements in functional performance in the 12-month-old group occurred at least 1 week after the same score had been achieved in the 3month-old group.

The number of rats that achieved plantar stepping, enabling them to complete footprint analysis, at each time point through 28 days was assessed and found to differ by age. The number of 12-month-aged rats that achieved plantar stepping by $28 \mathrm{dpi}$ was significantly lower than the 3-month-aged rats $\left[\mathrm{c}^{2}(3, N=31)=37.52\right.$, $p<0.0001$; Fig. 4b]. Rats that recovered the ability to take plantar steps with their hind limbs were tested on the footprint analysis task. At $28 \mathrm{dpi}, 12$-month-old rats that were able to plantar step demonstrated a significantly shorter stride length $(t(10)=2.53, p=0.0297$; Fig. 4d) and a trend toward narrower toe spread $(t(10)=1.192, p=0.0967$; Fig. $4 \mathrm{c})$ in comparison to the 3-month-old rats.
Middle-aged rats have significantly greater lesion volume rostral and caudal to the lesion epicenter

At $30 \mathrm{dpi}$, results from our lesion volume analysis showed a larger lesion volume in 12-month-old rats compared to that in 3-month-old rats; however, the volume of the lesion varied by proximity to lesion epicenter (Fig. 5a). At the lesion epicenter (360-540 $\mu \mathrm{m})$, both 3and 12-month-old animals demonstrated marked tissue damage and loss, with no significant difference in volume between age groups (Fig. $5 \mathrm{c}$ ). But in both rostral $(0-180 \mu \mathrm{m})$ and caudal $(720-900 \mu \mathrm{m})$ lesion epicenters, 12-month-old animals had significantly greater lesion volumes than 3-month-old animals $(t(10)=6.09$, $p<0.0001 /$ rostral, and $t(10)=4.64, p=0.0017 /$ caudal; Fig. $5 b$ and d).

\section{Microglial activation and gene expression 30 days after spinal cord injury is altered with age}

Immunostaining at $30 \mathrm{dpi}$ in both 3 - and 12-monthaged tissues revealed increased microglial activation, as defined by cell size and number, and reflected in pixel density of Iba1 staining microglia in comparison to naïve tissue (Fig. 6a). Aged tissue showed significantly greater Iba1 staining compared to young tissue $(t(6)=2.16$, $p=0.0487$; Fig. 6b). Comparative RT-PCR results (Fig. 6c) showed significantly increased gene expression in 12month-aged rat compared to 3-month-aged rats of pro-inflammatory marker $\mathrm{CD} 86(t(6)=7.26$, $p=0.0050)$, anti-inflammatory marker CD206 $(t(6)=5.75, p=0.0045)$, inflammatory cytokine TNF $\alpha$ $(t(6)=3.47, p=0.0127)$, and transcription factor $\mathrm{NFKB}(t(6)=4.98, p=0.0156)$. Relative fold changes 


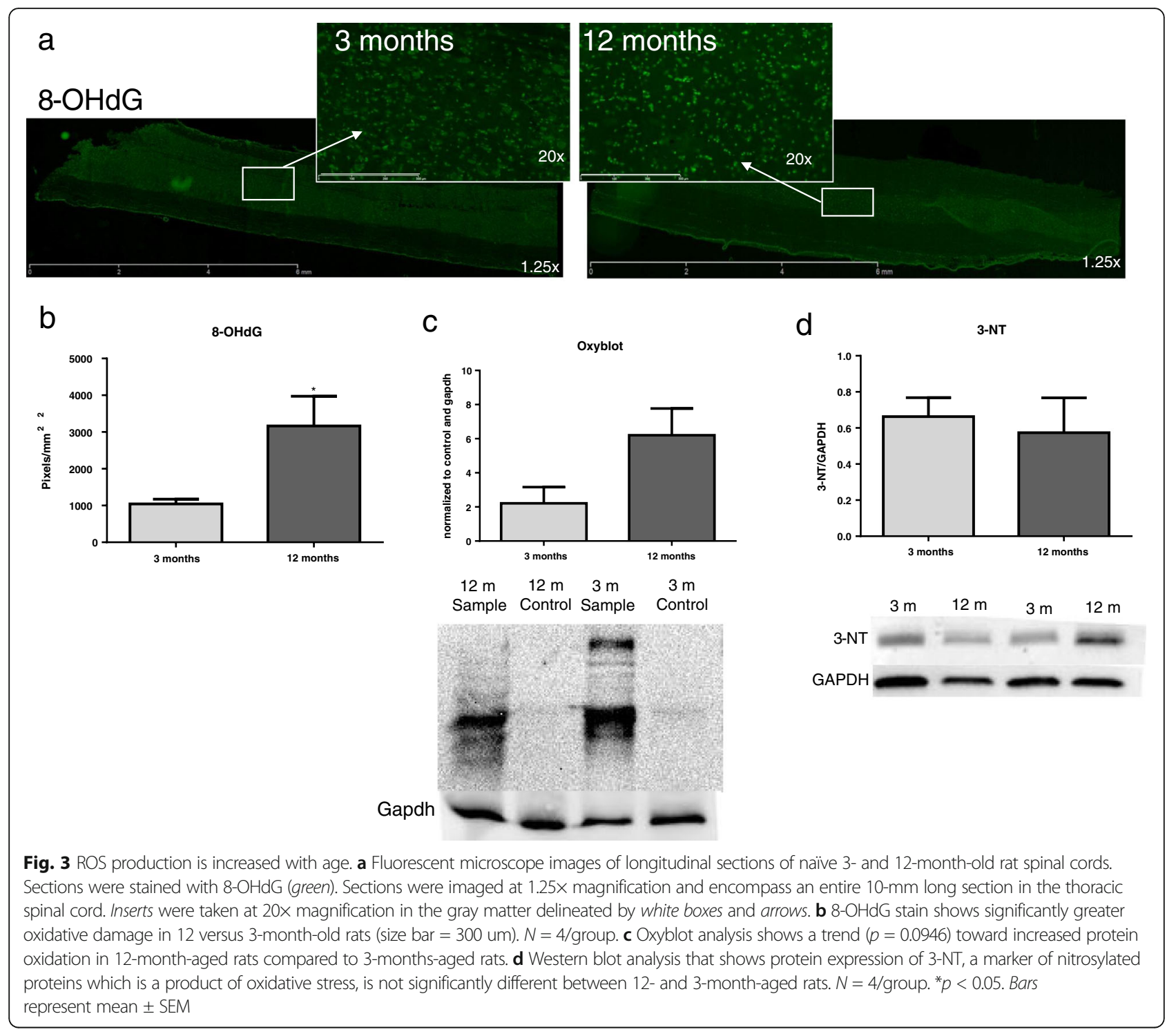

between 3- and 12-month-old rats for all genes tested listed in numerical form can be found in Table 3 under "30 dpi". An additional experiment comparing gene expression between naïve and injured groups within each age group was performed on selected genes to verify gene expression patterns (Table 4).

\section{Middle-aged rats show increased NOX2 component gene expression at $30 \mathrm{dpi}$}

To determine if NOX2 activity and expression after injury were influenced by age, tissue from injured 12- and 3 -month-aged rats at $30 \mathrm{dpi}$ was processed for comparative RT-PCR and analyzed for expression of target genes. Gene expression of the cytosolic subunit $\mathrm{p} 47^{\mathrm{PHOX}}$ and the membrane components $\mathrm{p} 22^{\mathrm{PHOX}}$ and gp $91^{\mathrm{PHOX}}$ were significantly increased in 12-month-aged rats compared to 3-month-aged rats $(t(6)=3.47, p=0.0404$; $t(6)=4.61, p=0.0182$ and $t(6)=2.94 ; p=0.0186$, respectively; Fig. 6d).

\section{Middle-aged rats show increased ROS production and oxidative stress at $30 \mathrm{dpi}$}

To determine if injured aged tissue showed differences in ROS production, tissue from 3- and 12-month-old rats was processed for Oxyblot and western blotting at $30 \mathrm{dpi}$. Oxyblot analysis revealed that 12-month-aged rats when compared to 3-month-aged rats demonstrated significantly increased protein oxidation $(t(6)=4.04$, $p=0.0156$; Fig. 7a), and western blotting of 3-NT, a marker of protein nitrosylation, demonstrated significantly increased protein nitrosylation $(t(6)=1.758$, $p=0.0038$; Fig. 7b). 


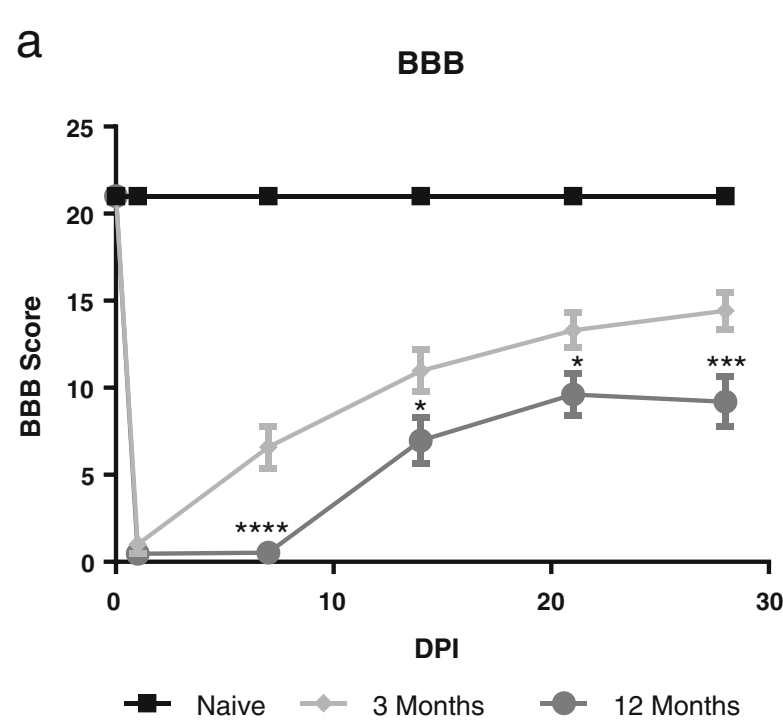

C

\section{Toe Spread}

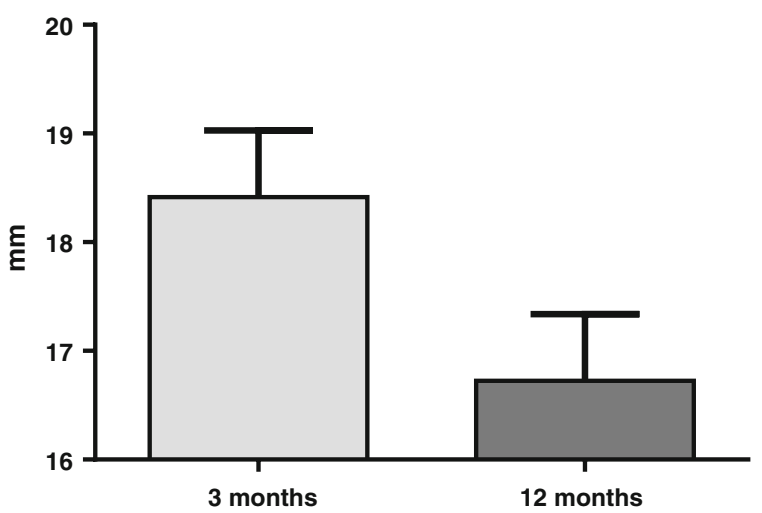

b

Successful Plantar Stepping

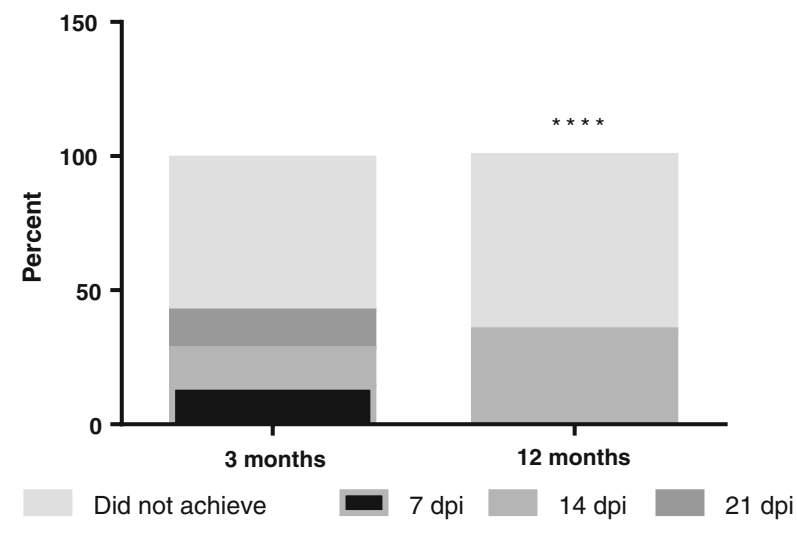

d

Stride Length

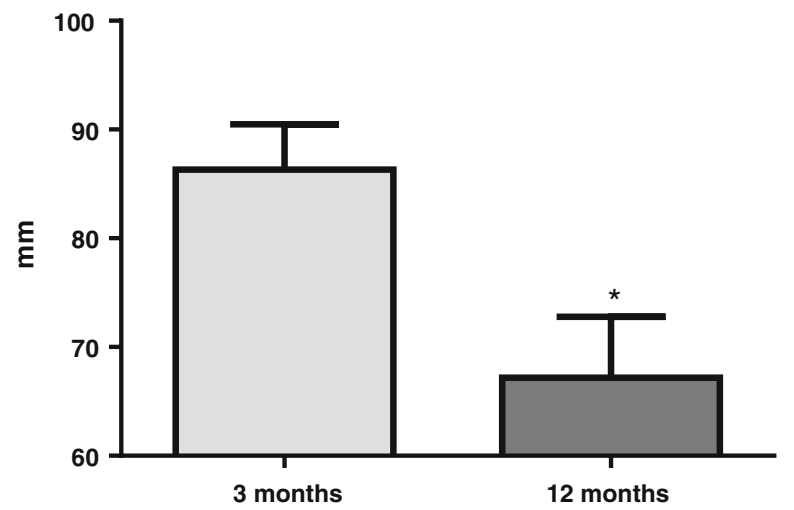

Fig. 4 Aged animals show diminished motor function recovery after injury. a At 1 dpi, no difference in performance in BBB scores were observed in injured rats. At all other time points (7, 14, 21, and 28 dpi), 12-month-old injured rats ( $n=17)$ showed significantly reduced BBB scores compared to 3 month-old rats $(n=18)$, indicating significantly impaired recovery to injury. $\mathbf{b}$ Aged animals show impaired ability to plantar step and complete footprint analysis task. Twelve-month-old rats $(n=17)$ show significantly diminished ability to plantar step in order to complete the footprint analysis task compared to 3-month-old rats $(n=14)$, indicating a diminished ability to take steps or strides. $\mathbf{c}$ At 28 dpi, toe spread analysis showed a trend in 12-month-old rats $(n=7)$ toward narrower toe spread compared to 3-month-old rats $(n=5)$. d 12-month-old rats $(n=7)$ showed significantly decreased stride length compared to 3-month-old rats $(n=5) .{ }^{*} p<0.05,{ }^{* *} p<0.005,{ }^{* * *} p<0.0005,{ }^{* * *} p<0.0001$. Bars represent mean \pm SEM

\section{Discussion}

This study demonstrates that aging alters the inflammatory environment in the 12-month-old rat spinal cord. Uninjured 12-month-old, middle-aged rats show increased microglial activation and NOX2 cytosolic subunit and pro-inflammatory gene expression and increased DNA oxidation when compared to 3-month-old, young adult rats. At $30 \mathrm{dpi}$, middle-aged rats show decreased functional recovery and increased lesion volume, microglial activation, NOX2 component and inflammatory gene expression, and protein oxidation and nitrosylation compared to young adult rats.
Previous work has shown increasing oxidative stress with age [8]. We now demonstrate that this increase is obvious in the CNS, with increased markers of oxidative stress in the middle-aged rat spinal cord both before and after injury. In naive middle-aged rats compared to young adult, increases in the DNA peroxidation marker 8-OHdG, but not of protein carbonylation (Oxyblot) and nitrosylation (3-NT), were observed. As mutations in DNA have been found by early middle age [5], DNA peroxidation may be one of the first signs of increasing ROS production, as part of a pro-inflammatory environment in an aging tissue [14]. As protein modifications 


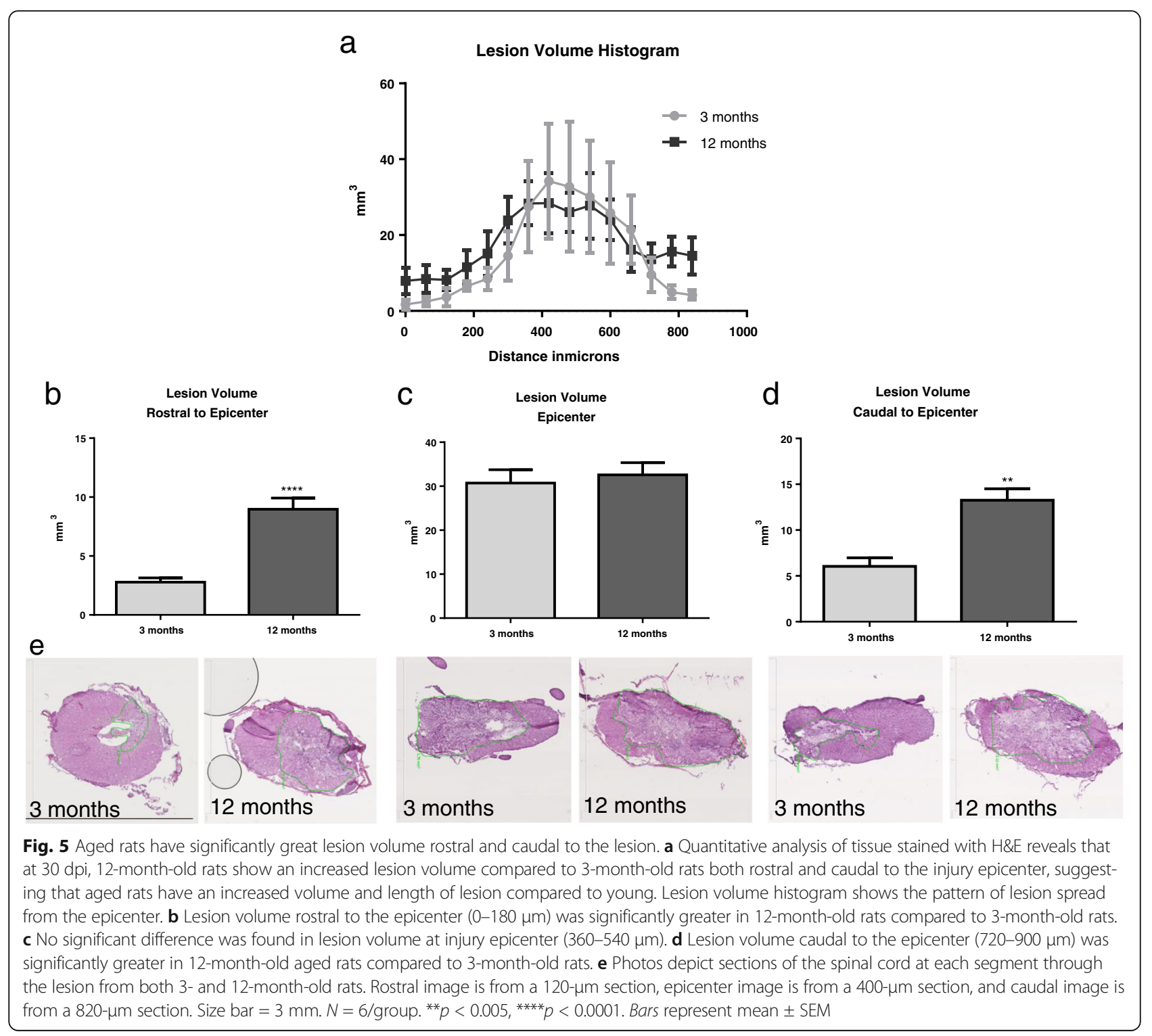

occur further downstream than DNA, age-related increases in protein carbonylation and nitrosylation markers may be more indicative of a hyperactive inflammatory response to injury.

The increased ROS production found in middle-aged rats coincides with our results showing increased microglial activity with age. Increased staining of the microglial marker Iba1 was coupled with increased proinflammatory gene expression of CD86 in middle-aged rats, suggesting that microglia are present in aged tissue in a pro-inflammatory state. Further, staining demonstrates alterations in microglial phenotype as defined previously [11], with 3-month-old rats showing a nonactivated phenotype with lengthy processes and a small cell body and 12-month-old rats showing a partially activated microglial phenotype, with an engorged, rounder shaped cell body. These findings in the spinal cord are similar to previous findings in the brain [14], suggesting an age-related pattern of the inflammatory response that is not impacted by regional differences between the spinal cord and the brain [17].

Interestingly, our gene expression experiments at $30 \mathrm{dpi}$ showed an increase in both pro-inflammatory- and antiinflammatory-related genes, suggesting that chronically after injury, all microglial activities are elevated, not only pro-inflammatory as seen in uninjured tissue. Previous work using aged mouse and female rat models of traumatic injury has shown a decrease in anti-inflammatory signaling and an increase in pro-inflammatory signaling at $24 \mathrm{~h}$ and $7 \mathrm{dpi}[18,19,21,25]$. In a traumatic brain injury 


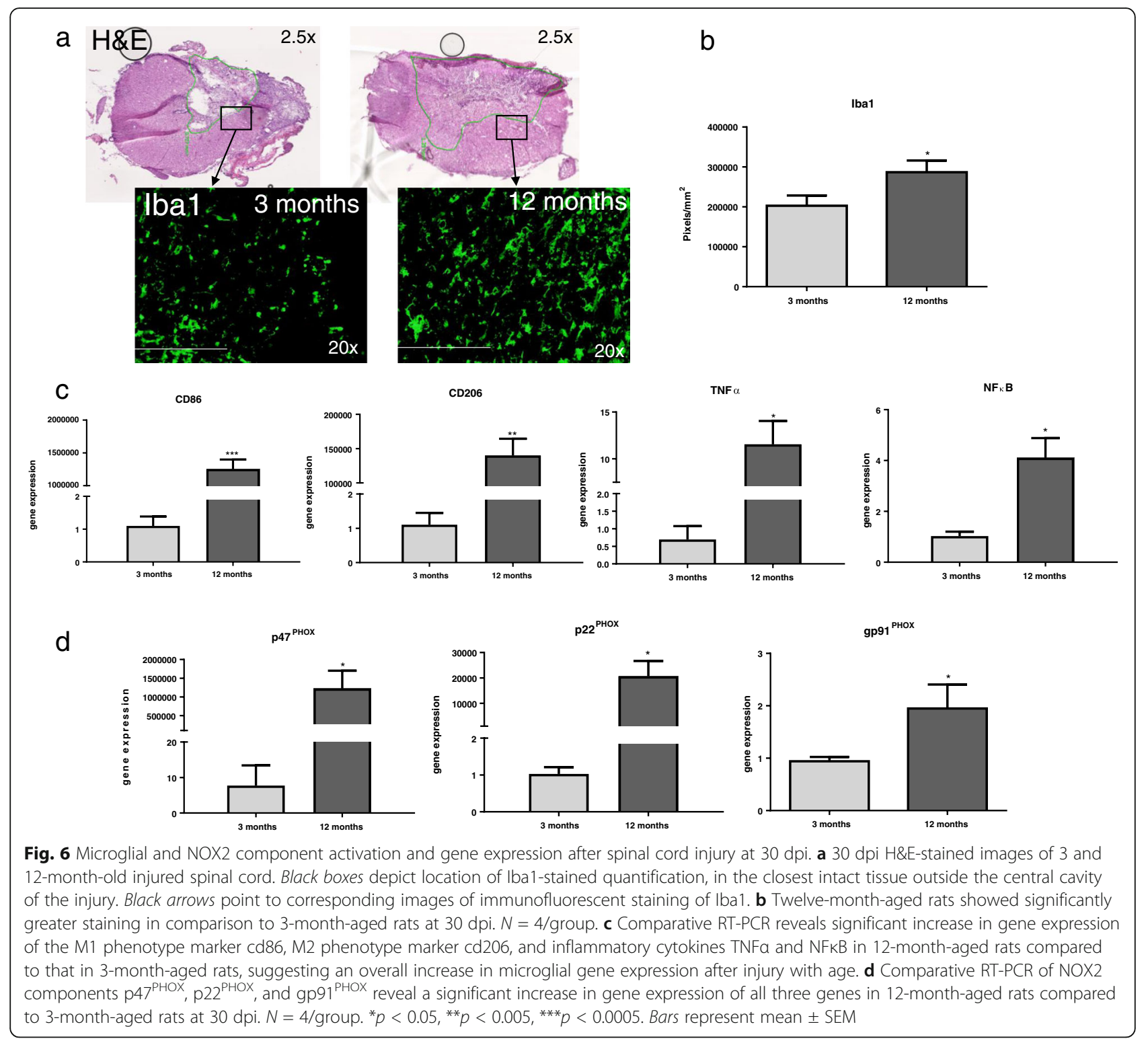

Table 4 Comparative gene fold changes by age group for significantly impacted genes

\begin{tabular}{|c|c|c|c|c|}
\hline \multicolumn{5}{|c|}{ Comparative fold change by age group } \\
\hline \multicolumn{2}{|l|}{3 months old } & \multirow{2}{*}{$\begin{array}{l}\text { Gene } \\
\text { tested }\end{array}$} & \multicolumn{2}{|l|}{12 months old } \\
\hline Naïve & $30 \mathrm{dpi}$ & & Naïve & $30 \mathrm{dpi}$ \\
\hline $1.467 \pm 0.8292$ & $4.481 \pm 1.179$ & CD86 & $0.6781 \pm 0.3546$ & $0.7444 \pm 0.08664$ \\
\hline $1.731 \pm 0.5850$ & $0.7586 \pm 0.5561$ & CD206 & $1.094 \pm 0.3027$ & $111,858 \pm 67,300$ \\
\hline $1.043 \pm 0.2966$ & $225.2 \pm 76.85$ & $\mathrm{p} 22^{\mathrm{PHOX}}$ & $1.005 \pm 0.06771$ & $218.9 \pm 132.1$ \\
\hline $1.491 \pm 0.8159$ & $3.134 \pm 2.551$ & $\mathrm{p} 47^{\mathrm{PHOX}}$ & $1.232 \pm 0.4360$ & *180,416 $\pm 31,468$ \\
\hline $1.001 \pm 0.02864$ & $28.02 \pm 3.662$ & gp91 ${ }^{\text {PHOX }}$ & $1.154 \pm 0.3588$ & $* 54.89 \pm 21.85$ \\
\hline
\end{tabular}

Table demonstrates the effect of injury on gene expression within age groups. The average of the naïve in both the 3- and 12-month-age groups was considered the control mean value. Each individual sample's fold change was compared to the control mean. Fold changes are presented in the table as mean values of all samples in each group \pm SEM. $N=4 /$ group ${ }^{*} p<0.005$ 


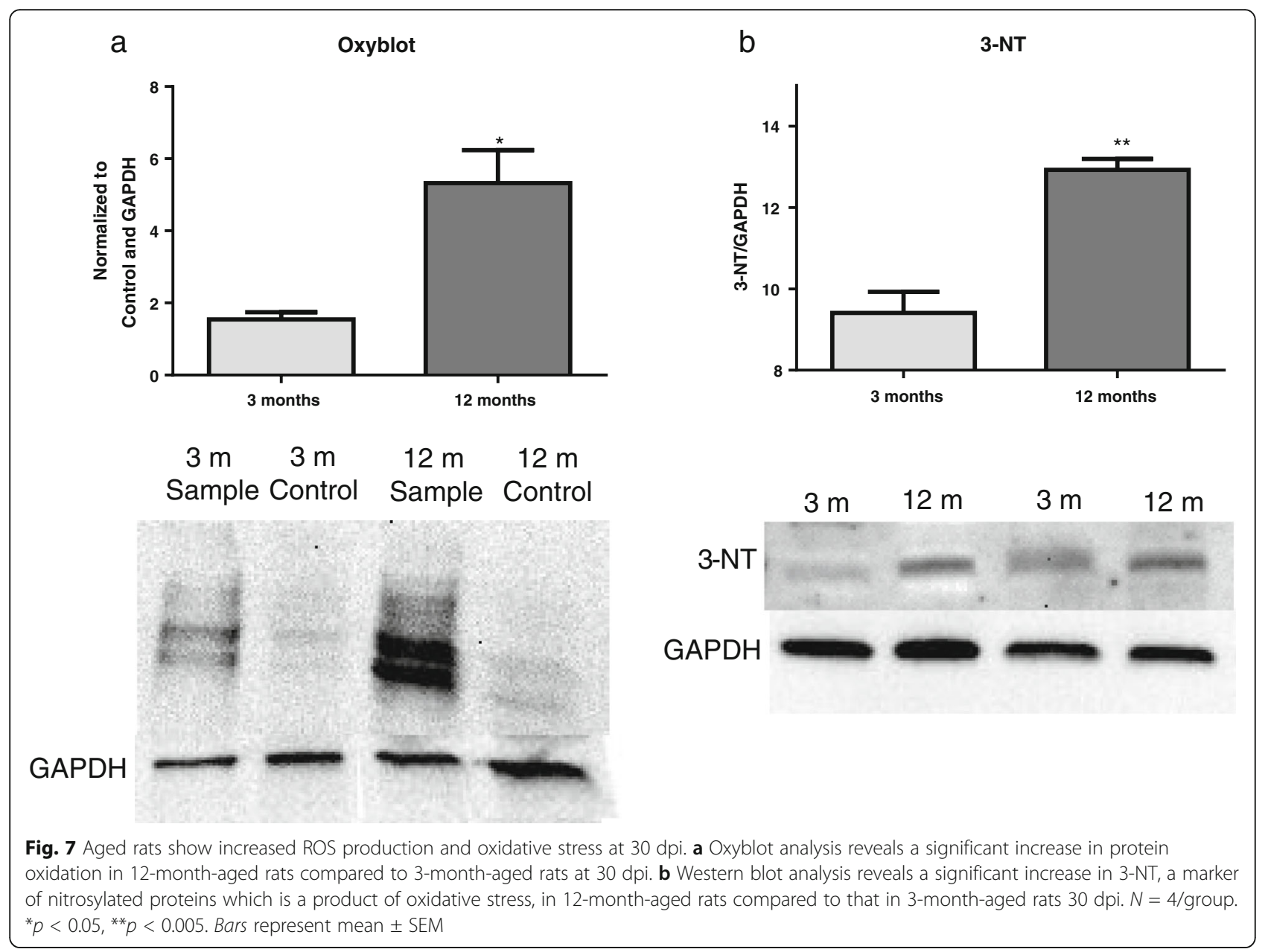

model with 23-month-old mice, a similar increase in both pro- and anti-inflammatory gene expression was observed at 24-h post-injury [35].Our findings at $30 \mathrm{dpi}$ suggest that a change in activation type may occur chronically post-injury that leads to a more active overall inflammatory response. Further, Morganti et al. [35] found that acute gene expression alterations were strongly dependent on peripheral monocyte infiltration; it is possible that the $30 \mathrm{dpi}$ data in our study is more microglial related due to the reduction in macrophage invasion at this later time point [36]. Future work should evaluate these earlier time points and contribution of peripheral and central inflammatory cells in 12-month-old rats to fully characterize our rodent model.

Increased gene expression of the activated NOX2 cytosolic subunit $\mathrm{p} 47^{\mathrm{PHOX}}$ but not the membrane components $\mathrm{p} 22^{\mathrm{PHOX}}$ or $\mathrm{gp} 91^{\mathrm{PHOX}}$ suggests that NOX2 expression is increased in middle-aged naïve rats, corresponding with the observed pro-inflammatory microglia. At $30 \mathrm{dpi}$, gene expression of both NOX2 membrane components $\mathrm{p} 22^{\mathrm{PHOX}}$ and $\mathrm{gp} 91^{\mathrm{PHOX}}$ and the cytosolic subunit $\mathrm{p} 47^{\mathrm{PHOX}}$ are elevated in middle-aged rats compared to young adults, suggesting that microglial NOX2 is "primed" prior to injury and activated more fully with injury. This could play a role in the increased ROS production we see in a middle-aged spinal cord. We and the others have shown that NOX2 is involved in microglial ROS production [22-24].

Our lesion volume experiments at $30 \mathrm{dpi}$ showed that at the epicenter of the injury, the lesion volume was not significantly different by age, but was significantly increased in middle-aged rats compared to young adults in sections of the spinal cord both rostral and caudal to the injury, demonstrating an increased volume farther from the lesion epicenter in middle-aged rats. Our results coincide with previous work showing increased lesion volume in aged female rats after SCI [19] and in a mouse model of TBI [25]. These findings demonstrate that injury severity is increased in middle-aged rats, which may be a result of the exaggerated inflammatory response leading to increased oxidative stress on cells. Control of motor function is distributed throughout the spinal cord with multiple interacting tracts, and recovery of function 
observable in injury models is largely due to the ability of the spinal networks to compensate for some loss of tissue [37]. Interestingly, previous work has shown that the increase of lesion volume and functional deficits is not completely linear, but with increasing injury severity, once a threshold proportion of tract is lost, loss of function is seen [38, 39]. The increased lesion volume found in our middle-aged rats would impact a greater number of tracts in the spinal cord, likely surpassing that threshold and contributing to the delayed functional recovery we observed.

Interestingly, naive middle-aged rats also show functional impairments, with altered stepping patterns with wider toe spread and longer stride length compared to young adult rats. Functional performance was more prominently affected in middle-aged rats than young adult after contusion SCI, at all time points examined out to $30 \mathrm{dpi}$. Middle-aged rats compared to young adult rats showed age-related delays in motor function with delayed general functional recovery, as demonstrated by lower scores on the BBB test, and worsened ability to complete the footprint task. These results agree with previous work in mouse and male and female rat models of aged SCI $[19,21,40]$. These previous studies demonstrate that 18-month-old female rats showed elevated base of support during walk both before and after injury [19], similar to our studies, while 12-month-old male rats consistently demonstrate impaired BBB function by $7 \mathrm{dpi}$ [40]. In contrast, 14-month-old male mice did not demonstrate functional impairment before injury, although this may be due to the use of only the locomotor score, similar to the BBB; however, a significant reduction in locomotor score was noted after injury [21], as in our study.

Interestingly, footprint analysis in middle-aged rats after SCI are opposite of what was seen in naïve, showing decreased stride lengths and narrower toe spread at $30 \mathrm{dpi}$ versus increased stride length and wider toe spread in naïve. Previous work in mouse models of SCI have shown that both stride length and toe spread decrease significantly after injury [41-43] and have suggested that the decrease may be indicative of sensory motor function deficits in the hind limbs due to injury. Thus, our findings of impaired recovery and altered stepping pattern in footprint analysis may be associated with an age-related decrease in precise motor control in the hind limbs.

\section{Conclusions}

Overall, the results of our study suggest that increasing age leads to a pro-inflammatory environment, with alterations to microglial activation, NOX2 enzyme component expression, and an increase in oxidative stress in the cellular environment that may contribute to worsened outcomes after
SCI. The initiating factor in these effects and the cause/effect relationship between each remains unclear and is an important consideration for the field moving forward. It is clear that there are intimate relationships between inflammation, oxidative damage, and NOX2, and the current work contributes to understanding that all three play a role in motor function and post-injury recovery. However, more work is needed to understand which, if not all three, the essential component is. We currently hypothesize that age-related changes to ROS production caused by increased microglial activation and NOX2 expression are associated with an exaggerated chronic inflammatory response to injury.

With the rise in SCI in the aging population, the results of this study suggest that increased inflammatory response may be an important factor to be considered in therapeutic interventions after injury and that age should be considered when developing a therapeutic treatment plan. Further, previous work has demonstrated that inhibition of the NOX enzyme can decrease oxidative stress and inflammation. Due to the association of NOX2 with both ROS production and microglial activity, our findings suggest a potential avenue for NOX2 inhibitory treatment options to quell the exaggerated inflammatory response and should be a topic of interest for future research.

\section{Abbreviations \\ CNS: Central nervous system; DPI: Days post-injury; NOX: NADPH oxidase; ROS: Reactive oxygen species; SCl: Spinal cord injury}

\section{Acknowledgements}

The authors would like to acknowledge the editorial assistance provided by Ms. I. von Leden. The opinions or assertions contained herein are the private ones of the author(s) and are not to be construed as official or reflected as the views of the DoD or the USUHS.

\section{Funding}

This work was funded by the NINDS/NIH (Grant number 1R01NS07366701A1) and a pilot grant from the Uniformed Services University. R. von Leden was supported by the NINDS/NIH (Grant number 1F31NS090737-01A1).

\section{Availability of data and materials}

All data generated or analyzed during this study are included in this published article.

\footnotetext{
Authors' contributions

RV conceived of the study; carried out and performed the statistical analyses for all outcome measures, including the function, oxidative stress, gene expression, and immunoassays; and drafted the manuscript. GK assisted in the design and measurement of the functional outcomes and immunoassays. KM participated in the design of the gene expression studies and helped to draft the manuscript. KB participated in the design and coordination of the study and helped to draft the manuscript. All authors read and approved the final manuscript.
}

\section{Ethics approval}

All animal procedures were approved by the Uniformed Services University IACUC and complied fully with the principles set forth in the "Guide for the Care and Use of Laboratory Animals" prepared by the Committee on Care and Use of Laboratory Animals of the Institute of Laboratory Resources, National Research Council (DHEW pub. No. (NIH) 85-23, 2985). 


\section{Consent for publication}

Not Applicable.

\section{Competing interests}

The authors declare that they have no competing interests.

\section{Publisher's Note}

Springer Nature remains neutral with regard to jurisdictional claims in published maps and institutional affiliations.

\section{Received: 23 March 2017 Accepted: 4 August 2017} Published online: 18 August 2017

\section{References}

1. NSCISC. National Spinal Cord Injury Statistical Center, facts and figures at a glance. Birmingham: University of Alabama at Birmingham; 2016. p. 2016.

2. Dumont RJ, Okonkwo DO, Verma S, Hurlbert RJ, Boulos PT, Ellegala DB, et al. Acute spinal cord injury, part I: pathophysiologic mechanisms. Clin Neuropharmacol. 2001;24:254-64.

3. Ronsyn MW, Berneman ZN, Van Tendeloo VFI, Jorens PG, Ponsaerts P. Can cell therapy heal a spinal cord injury? Spinal Cord. 2008:46:532-9.

4. Jain NB, Ayers GD, Peterson EN, Harris MB, Morse L, O'Connor KC, et al. Traumatic spinal cord injury in the United States, 1993-2012. JAMA. 2015; 313:2236-43.

5. Lu T, Pan Y, Kao S-Y, Li C, Kohane I, Chan J, et al. Gene regulation and DNA damage in the ageing human brain. Nature. 2004;429:883-91.

6. Groah SL, Charlifue S, Tate D, Jensen MP, Molton IR, Forchheimer M, et al. Spinal cord injury and aging: challenges and recommendations for future research. Am J Phys Med Rehabil Assoc Acad Physiatr. 2012;91:80-93.

7. Harman D. Free radical theory of aging. Mutat Res. 1992;275:257-66

8. Kregel $\mathrm{KC}$, Zhang HJ. An integrated view of oxidative stress in aging: basic mechanisms, functional effects, and pathological considerations. Am J Physiol - Regul Integr Comp Physiol. 2007;292:R18-36.

9. Gao H-M, Zhou H, Hong J-S. NADPH oxidases: novel therapeutic targets for neurodegenerative diseases. Trends Pharmacol Sci. 2012;33:295-303.

10. Byrnes KR, Washington PM, Knoblach SM, Hoffman E, Faden Al. Delayed inflammatory mRNA and protein expression after spinal cord injury. J Neuroinflammation. 2011:8:130

11. Loane DJ, Byrnes KR. Role of microglia in neurotrauma. Neurother J Am Soc Exp Neurother. 2010;7:366-77.

12. Sierra A, Gottfried-Blackmore AC, McEwen BS, Bulloch K. Microglia derived from aging mice exhibit an altered inflammatory profile. Glia. 2007;55:412-24.

13. Salminen A, Ojala J, Kaarniranta K, Haapasalo A, Hiltunen M, Soininen H. Astrocytes in the aging brain express characteristics of senescenceassociated secretory phenotype. Eur J Neurosci. 2011:34:3-11.

14. Norden DM, Muccigrosso MM, Godbout JP. Microglial priming and enhanced reactivity to secondary insult in aging, and traumatic CNS injury, and neurodegenerative disease. Neuropharmacology. 2015;96 Pt A:29-41.

15. Batchelor PE, Tan S, Wills TE, Porritt MJ, Howells DW. Comparison of inflammation in the brain and spinal cord following mechanical injury. J Neurotrauma. 2008;25:1217-25.

16. Schnell L, Fearn S, Klassen H, Schwab ME, Perry VH. Acute inflammatory responses to mechanical lesions in the CNS: differences between brain and spinal cord. Eur J Neurosci. 1999:11:3648-58.

17. Zhang B, Gensel JC. Is neuroinflammation in the injured spinal cord different than in the brain? Examining intrinsic differences between the brain and spinal cord. Exp Neurol. 2014;258:112-20.

18. Fenn AM, Hall JCE, Gensel JC, Popovich PG, Godbout JP. IL-4 signaling drives a unique arginase $+/ \mathrm{IL}-1 \beta+$ microglia phenotype and recruits macrophages to the inflammatory CNS: consequences of age-related deficits in IL-4Ra after traumatic spinal cord injury. J Neurosci. 2014;34:8904-17.

19. Hooshmand MJ, Galvan MD, Partida E, Anderson AJ. Characterization of recovery, repair, and inflammatory processes following contusion spinal cord injury in old female rats: is age a limitation? Immun Ageing A. 2014;11:15.

20. Ritzel RM, Patel AR, Pan S, Crapser J, Hammond M, Jellison E, et al. Age- and location-related changes in microglial function. Neurobiol Aging. 2015;36:2153-63.

21. Zhang B, Bailey WM, Braun KJ, Gensel JC. Age decreases macrophage IL-10 expression: implications for functional recovery and tissue repair in spinal cord injury. Exp Neurol. 2015;273:83-91.
22. Zhang B, Bailey WM, McVicar AL, Gensel JC. Age increases reactive oxygen species production in macrophages and potentiates oxidative damage after spinal cord injury. Neurobiol Aging. 2016;47:157-67.

23. Cooney SJ, Zhao Y, Byrnes KR. Characterization of the expression and inflammatory activity of NADPH oxidase after spinal cord injury. Free Radic Res. 2014:48:929-39.

24. Khayrullina G, Bermudez S, Byrnes KR. Inhibition of NOX2 reduces locomotor impairment, inflammation, and oxidative stress after spinal cord injury. J Neuroinflammation. 2015:12:172.

25. Kumar A, Stoica BA, Sabirzhanov B, Burns MP, Faden Al, Loane DJ. Traumatic brain injury in aged animals increases lesion size and chronically alters microglial/macrophage classical and alternative activation states. Neurobiol Aging. 2013;34:1397-411.

26. Gwak YS, Hains BC, Johnson KM, Hulsebosch CE. Locomotor recovery and mechanical hyperalgesia following spinal cord injury depend on age at time of injury in rat. Neurosci Lett. 2004;362:232-5.

27. Kilkenny C, Browne WJ, Cuthill IC, Emerson M, Altman DG. Improving bioscience research reporting: the ARRIVE guidelines for reporting animal research. PLoS Biol. 2010;8:e1000412.

28. Cooney SJ, Bermudez-Sabogal SL, Byrnes KR. Cellular and temporal expression of NADPH oxidase (NOX) isotypes after brain injury. J Neuroinflammation. 2013:10:155.

29. Basso DM, Beattie MS, Bresnahan JC. A sensitive and reliable locomotor rating scale for open field testing in rats. J Neurotrauma. 1995:12:1-21.

30. Kunkel-Bagden E, Dai HN, Bregman BS. Methods to assess the development and recovery of locomotor function after spinal cord injury in rats. Exp Neurol. 1993;119:153-64

31. Loane DJ, Pocivavsek A, Moussa CE-H, Thompson R, Matsuoka Y, Faden Al, et al. Amyloid precursor protein secretases as therapeutic targets for traumatic brain injury. Nat Med. 2009;15:377-9.

32. Moritz KE, Geeck K, Underly RG, Searles M, Smith JS. Post-operative environmental enrichment improves spatial and motor deficits but may not ameliorate anxiety- or depression-like symptoms in rats following traumatic brain injury. Restor Neurol Neurosci. 2014;32:701-16.

33. Donnelly DJ, Gensel JC, Ankeny DP, van Rooijen N, Popovich PG. An efficient and reproducible method for quantifying macrophages in different experimental models of central nervous system pathology. J Neurosci Methods. 2009;181:36-44.

34. Selwyn R, Hockenbury N, Jaiswal S, Mathur S, Armstrong RC, Byrnes KR. Mild traumatic brain injury results in depressed cerebral glucose uptake: an (18)FDG PET study. J Neurotrauma. 2013;30:1943-53.

35. Morganti JM, Riparip L-K, Chou A, Liu S, Gupta N, Rosi S. Age exacerbates the CCR2/5-mediated neuroinflammatory response to traumatic brain injury. J Neuroinflammation. 2016:13:80

36. Jin X, Ishii H, Bai Z, Itokazu T, Yamashita T. Temporal changes in cell marker expression and cellular infiltration in a controlled cortical impact model in adult male C57BL/6 mice. PLoS One. 2012;7:e41892.

37. Fouad K, Hurd C, Magnuson DSK. Functional testing in animal models of spinal cord injury: not as straight forward as one would think. Front Integr Neurosci. 2013;7:85.

38. Loy DN, Talbott JF, Onifer SM, Mills MD, Burke DA, Dennison JB, et al. Both dorsal and ventral spinal cord pathways contribute to overground locomotion in the adult rat. Exp Neurol. 2002;177:575-80.

39. Schucht P, Raineteau O, Schwab ME, Fouad K. Anatomical correlates of locomotor recovery following dorsal and ventral lesions of the rat spinal cord. Exp Neurol. 2002;176:143-53.

40. Gwak YS, Hains BC, Johnson KM, Hulsebosch CE. Effect of age at time of spinal cord injury on behavioral outcomes in rat. J Neurotrauma. 2004;21:983-93.

41. Blakeman KH, Hao J-X, Xu X-J, Jacoby AS, Shine J, Crawley JN, et al. Hyperalgesia and increased neuropathic pain-like response in mice lacking galanin receptor 1 receptors. Neuroscience. 2003;117:221-7.

42. Hygge-Blakeman K, Brumovsky P, Hao J-X, Xu X-J, Hökfelt T, Crawley JN, et al. Galanin over-expression decreases the development of neuropathic pain-like behaviors in mice after partial sciatic nerve injury. Brain Res. 2004; 1025:152-8

43. Beare JE, Morehouse JR, DeVries WH, Enzmann GU, Burke DA, Magnuson DSK, et al. Gait analysis in normal and spinal contused mice using the TreadScan system. J Neurotrauma. 2009;26:2045-56. 